\title{
EL CONCEPTO DE LIBERTAD RELIGIOSA EN ALGUNOS INSTRUMENTOS INTERNACIONALES SOBRE DERECHOS HUMANOS QUE VINCULAN JURÍDICAMENTE AL ESTADO DE CHILE
}

\author{
THE CONCEPT OF RELIGIOUS FREEDOM IN SOME \\ INTERNATIONAL INSTRUMENTS ABOUT HUMAN RIGHTS \\ BINDING TO THE STATE OF CHILE
}

Elvira Badilla Poblete*

\begin{abstract}
RESUMEN: Este trabajo indaga sobre el concepto de libertad religiosa contenido en algunos instrumentos internacionales de derechos humanos vinculantes jurídicamente para el Estado de Chile. Tras una breve introducción en la que se realiza un recorrido cronológico en la historia de los derechos humanos y en la que se intenta dar cuenta de la presencia siempre relevante de este derecho en dicha historia, se hace una revisión de los instrumentos internacionales de carácter universal y regional seleccionados y su contenido en materia de libertad religiosa, comparando los diferentes aportes que han podido hacer unos y otros al concepto de libertad religiosa según la doctrina. Junto al análisis de los instrumentos internacionales que se realiza se han considerado las fórmulas de protección de este derecho existentes en el Derecho Internacional de los Derechos Humanos con una especial atención en el Sistema Interamericano de Protección de los Derechos Humanos y el tratamiento que ha dado a la libertad religiosa.
\end{abstract}

Palabras clave: Libertad religiosa, libertad de conciencia, Derecho Internacional de los Derechos Humanos.

ABSTRACT: This work researches the concept of religious freedom in some international instruments about Human Rights which are binding to the State of Chile. After a brief introduction respect the development of the Human Rights in History, where is possible to see its relevance, a revision of global and local international instruments is made with reference to religious freedom. Follow a comparison between the contributions made by many authors in this subject. Finally, a study about the mechanisms to protect the religious freedom considerated in the International Human Rights Law, with special attention in the Inter-American System of Protection of Human Rights and the treatment that the OAS has given to religious freedom.

Key words: religious freedom, freedom of conscience, International Human Rights Law.

\footnotetext{
* Profesora de Derecho Internacional de la Universidad Católica del Norte (Chile). Licenciada en Derecho por la Pontificia Universidad Católica de Chile. Abogado. Correo electrónico: ebadilla@ucn.cl. Becaria MECESUP UCN.

Observación: Este trabajo (con algunas modificaciones) fue realizado para el curso "Libertad religiosa en derecho comparado", dictado por la Dra. Ana María Celis en el programa de Doctorado en Derecho de la Pontificia Universidad Católica de Chile, correspondiente al segundo semestre de 2007.
} 


\section{A MODO DE INTRODUCCIÓN}

Es objetivo de este trabajo revisar el concepto del derecho a la libertad religiosa contenido en algunos instrumentos de Derecho internacional de los derechos humanos que vinculan jurídicamente al Estado de Chile ${ }^{1}$.

La libertad religiosa como derecho humano, esto es, un derecho inherente a la persona humana por su propia naturaleza y dignidad, aparece como uno de los primeros derechos respecto de los que se ha reclamado su reconocimiento, respeto y garantía en la historia.

Podemos mencionar como un antecedente histórico relevante en la materia, la persecución de que fueron objeto los cristianos en los tiempos del Imperio Romano. En el año 311, en el contexto de un imperio romano politeísta y tras una cruenta persecución a los cristianos, el emperador Galerio promulga el Edicto de Galerio, poniendo fin a la persecución de los cristianos ${ }^{2}$. Sin embargo como dan cuenta los historiadores es en el año 313, con el Edicto de Milán obra de Constantino I y Licinio en el que "se proclama la más absoluta libertad religiosa" ${ }^{3}$. En su texto el edicto proclama: "(...) conceder tanto a los cristianos como a todos los demás, facultad de seguir libremente la religión que cada cual quiera" (...) y permitir de ahora en adelante a todos los que quieran observar la religión cristiana, hacerlo libremente y sin que esto les suponga ninguna clase de inquietud y molestia (...) a los otros ciudadanos (los no cristianos) les ha sido concedida la facultad de observar libre y abiertamente la religión que hayan escogido como es propio de la paz de nuestra época".

Posteriormente y en el marco del esquema feudal imperante en Europa, surge otro documento considerado dentro de la cronología de los derechos humanos, la Carta Magna de 1215, en la que se consagran "libertades y privilegios" y no derechos propiamente tales ${ }^{5}$. Entre estas libertades consideradas relevantes en la historia de los derechos humanos, el rey reconoce la libertad de la Iglesia (que se debe entender como libertad respecto del rey).

Como una forma de acabar con las guerras de religiones surge en Europa una fórmula jurídica que cristaliza la filosofía de la tolerancia ${ }^{6}$, el Edicto de Nantes, llamado "sobre la pacificación de los disturbios de este reino" promulgado en Nantes en abril de 1598 bajo la firma de Enrique IV Rey de Francia ${ }^{7}$. Sin perjuicio del predominio de la dimensión política por sobre la religiosa, este documento contiene un "reconocimiento a

\footnotetext{
1 Se trata de instrumentos internacionales de carácter multilateral universales o regionales. Teniendo en cuenta que la Santa Sede posee subjetividad internacional, la que ha sido reconocida a través de la historia, cabría considerar la existencia de concordatos vigentes en Chile (acuerdos internacionales entre el Estado y la Santa Sede) sugerimos revisar al respecto a SALINAS (2004) pp. 240-251 y PRECHT (2001) pp. 83-129.

2 BLÁZQUEZ (1974)

3 LlORCA (1976) p. 375.

4 ARTOla (1982) pp. 21-22, en esta obra el autor reproduce el Edicto de Milán, según Lactancio: De mortibus persecutorum (c.318-321).

5 PÁRAMO y ANSUÁtegui (1998) p. 749.

${ }^{6}$ Ver sobre la filosofía de la tolerancia a PECES-BARBA (1998) pp. 265-373.

7 PECES-BARBA (1998) pp.688-691.
} 
la dignidad de la persona humana y de su derecho a agruparse libremente para adorar a Dios de acuerdo a su conciencia" ${ }^{\text {. }}$

Este Edicto, utiliza en el preámbulo, la expresión "libertad de sus conciencias", lo que para Peces-Barba: “(...) supone cronológicamente, una de las primeras menciones de ese término"'.

El Edicto de Nantes establece la libertad de conciencia para los protestantes reformados de manera general y amplia y la libertad de culto restringida solo a ciertos lugares ${ }^{10}$. Prohíbe que los hijos sean bautizados, sin autorización de sus padres, en la religión diferente a la de sus progenitores. Esto referido a la Religión Católica y a la Protestante Reformada ${ }^{11}$. Para el ejercicio de esta libertad de conciencia y de culto reconoce otras libertades como la de prensa e imprenta, de educación, de inviolabilidad del domicilio, de circulación y de reunión ${ }^{12}$.

Otras fórmulas jurídicas fueron utilizadas para el reconocimiento del principio de la tolerancia, la libertad religiosa y de conciencia en época de la Reforma y Contrarreforma, tales como la Paz de Augsburgo de 1555 y la Paz de Westfalia de 1648, instrumentos internacionales en los que se reconoce el derecho a emigrar para aquellos que no profesaban la religión oficial ${ }^{13}$.

En los siglos XVII y XVIII la cuestión de la tolerancia y la libertad de conciencia y religión sigue siendo un tema controvertido. Pero ya en esta época su discusión se enmarca dentro del reconocimiento de los derechos civiles y políticos ${ }^{14}$ lo que arroja como fruto diversas declaraciones de reconocimiento de derechos del hombre en el siglo XVIII.

En la Declaración de Derechos de Virginia de 1776, primera declaración que contiene un catálogo específico de derechos del hombre y del ciudadano, se consagra el derecho a la libertad religiosa "...al men are equally entitled to the free excercise of religion..." (Art. 16) ${ }^{15}$.

Posteriormente en Francia, la Declaración de los Derechos del Hombre y del Ciudadano de 1789, expresión máxima de la Revolución Francesa, contiene en el artículo 10 "el legado más universal de la revolución francesa a la historia de la tutela de la libertad religiosa"16 el que dice: "Nadie debe ser inquietado por sus opiniones, incluso religiosas, a condición de que su manifestación no altere el orden público establecido por la ley".

Sin duda es la Revolución Francesa la que con creces contribuyó al desarrollo posterior del reconocimiento de los derechos individuales, derechos inalienables, impres-

\footnotetext{
8 PeCES-BARBA (1998) p. 687.

9 PECES-BARBA (1998) p. 693.

10 PeCes-Barba (1998) p. 698.

11 PeCES-BARBa (1998) p. 696.

12 PeCES-BARBa (1998) p. 698.

13 TRUYOL (1984) p. 15

14 TRUYOL (1984) p. 16

15 SALinas (2004) pp. 42-46.

16 SAlinas (2004) p. 45 siguiendo el pensamiento de Pedro Lombardía.
} 
criptibles e inherentes a la personalidad humana. Derechos que se reconocieron al individuo en su calidad de tal y no por el hecho de pertenecer a un estamento o grupo religioso determinado.

Tras los acontecimientos del siglo XVIII, la libertad religiosa, junto a los demás derechos fundamentales se ha ido plasmando en las constituciones, leyes y tratados hasta nuestros días ${ }^{17}$.

La garantía y protección universal de estos derechos llega tras las dos guerras mundiales, se reconoce que el problema del respeto, protección y garantía de los derechos humanos es universal y no compete solo a los Estados.

Punto de partida del desarrollo actual de los derechos humanos es la Carta de las Naciones Unidas. Si bien la Carta no contiene un catálogo de derechos y no define lo que debe entenderse por derechos humanos, en su preámbulo ${ }^{18}$ los Estados "reafirman la fe en los derechos fundamentales del hombre, en la dignidad y el valor de la persona humana"19 y en el artículo primero se consagra, dentro de los propósitos de la Carta, que los Estados deben desarrollar y estimular el respeto a los derechos humanos y libertades fundamentales sin distinción de raza, sexo, idioma o religión.

Sigue a esta Carta la Declaración Universal de los Derechos Humanos (1948); el Convenio Europeo para la salvaguardia de los derechos humanos y las libertades fundamentales (1950) instrumento este último que da inicio a la tutela judicial de los derechos humanos en el ámbito internacional, estableciendo un órgano jurisdiccional ante el cual se pueden reclamar las violaciones a los derechos reconocidos. Con posterioridad a este instrumento surgen otros pactos internacionales de carácter universal que revisaremos en la sección siguiente de este trabajo. En el año 1969 surge la Convención Americana sobre Derechos Humanos, de particular interés para nuestro ordenamiento jurídico. Este convenio se enmarca en los términos del Convenio Europeo para efectos de respetar y garantizar los derechos humanos.

Tras este breve recorrido en la historia de los derechos humanos, no cabe duda, que la lucha por el reconocimiento de los derechos del hombre tiene su origen en el reconocimiento a la libertad religiosa y de conciencia.

\footnotetext{
17 BASTERRA (1989) p.122.

18 En conformidad al artículo $31 \mathrm{n}^{\circ} 2$ de la Convención de Viena sobre el Derecho de los Tratados (ratificada por Chile en 1980 y publicada en el Diario Oficial el 22 de julio de 1981) "Para los efectos de la interpretación de un tratado, el contexto comprenderá, además del texto, incluidos su preámbulo y anexos (...)". Es importante destacar que la práctica y la doctrina coinciden en asignarle valor jurídico al preámbulo, tanto como a su parte dispositiva. Ver: LlANOS (2005) pp. 73-75, quien además cita el Informe Jurídico $\mathrm{N}^{\circ} 123$ del Ministerio de Relaciones Exteriores de Chile del año 1967 el que expresa la postura chilena al respecto; RODRÍGUEZ (2006) pp. 185-186; MARIÑO (2005) p. 354.

${ }^{19} \mathrm{La}$ Carta de las Naciones Unidas se firmó el 26 de junio de 1945 en la Conferencia de las Naciones Unidas sobre Organización Internacional y entró en vigor el 24 de octubre de ese año. Este tratado consta de un preámbulo, 111 artículos más el Estatuto de la Corte Internacional de Justicia.
} 


\section{INSTRUMENTOS INTERNACIONALES QUE ABORDAN O SE REFIEREN A LA LIBERTAD RELIGIOSA Y QUE VINCULAN JURÍDICAMENTE AL ESTADO DE CHILE}

En esta sección expondremos aquellos instrumentos internacionales a los cuales Chile se encuentra vinculado jurídicamente y que hemos considerado de mayor relevancia en relación con dos aspectos que son inseparables: la relevancia que dichos instrumentos han tenido en el desarrollo del derecho internacional de los derechos humanos y el tratamiento que dichos instrumentos han hecho del contenido del derecho a la libertad religiosa, también relevante para el desarrollo de este último derecho.

Además se han incluido algunos instrumentos importantes en el desarrollo -en particular- de la libertad religiosa como derecho humano y también están aquellos instrumentos importantes para el desarrollo progresivo de la protección y promoción de los derechos humanos, que sin hacer mención al contenido de la libertad religiosa consagran este derecho, relevándolo ${ }^{20}$.

\section{A) INSTRUMENTOS DE CARÁCTER UNIVERSAL}

\section{La Declaración Universal de Derechos Humanos}

Esta Declaración (en adelante la Declaración) considerada piedra angular ${ }^{21}$ en el desarrollo de los derechos humanos -y en particular en el desarrollo de la libertad religiosa como derecho humano ${ }^{22}$ - fue proclamada por la Asamblea General de las Naciones Unidas el 10 de diciembre de 1948.

En su preámbulo encontramos dos ideas vinculadas a la libertad religiosa, el reconocimiento a la dignidad humana como fundamento de los derechos humanos y el derecho a disfrutar de la libertad de creencias. Luego en su artículo $2^{\circ}$ numeral 1 señala que "Toda persona tiene todos los derechos y libertades proclamados en esta Declaración, sin distinción alguna de raza, color, sexo, idioma, religión, opinión política o de cualquier otra índole, origen nacional o social, posición económica, nacimiento o cualquier otra condición”. Además, la Declaración consagra el principio de igualdad ante la ley de los seres humanos (art. 7).

\footnotetext{
${ }^{20}$ En materia de derechos humanos, según información de la Dirección de Derechos Humanos del Ministerio de Relaciones Exteriores, completan las cuatro decenas los tratados (solo tratados) vigentes en Chile a ello se deben sumar otros dieciséis tratados que solo han sido ratificados, suscritos o en trámite. Ver detalle en el sitio oficial del Ministerio de Relaciones Exteriores en http://www.minrel.gov.cl/webMinRel/ home.do?sitio=1. Fecha de última consulta: 27 de enero de 2008.

21 CARrillo (1999) pp. 85-96.

A modo de ejemplo: el preámbulo del Convenio Europeo para la salvaguardia de los derechos humanos y las libertades fundamentales, menciona la Declaración como un antecedente de relevancia para el mecanismo de protección que estaban por crear los miembros del Consejo de Europa. En el mimo sentido lo hacen los Pactos internacionales de derechos civiles y políticos y de derechos económicos sociales y culturales; la Convención americana sobre derechos humanos (Pacto de San José de Costa Rica); la Carta Africana de derechos humanos y de los pueblos (Carta de Banjul).
}

22 DAVIS (2001) p. 23 
En el artículo 18 consagra, específicamente, la libertad religiosa: "Toda persona tiene derecho a la libertad de pensamiento, de conciencia y de religión; este derecho incluye la libertad de cambiar de religión o de creencia, así como la libertad de manifestar su religión o su creencia, individual y colectivamente, tanto en público como en privado, por la enseñanza, la práctica, el culto y la observancia”. Se refiere a la libertad religiosa en sus dos aspectos individual y colectivo luego, pareciera adecuado también agregar a esta selección el artículo 20 de la Declaración, que consagra la libertad de reunión y asociación y el derecho a no ser obligado a pertenecer a una asociación ${ }^{23}$.

Vinculado a la libertad de pensamiento, de conciencia y de religión consagradas en el artículo 18 de la Declaración encontramos el art. 26, que contempla el derecho a la educación y particularmente el No 2 se refiere a que mediante el ejercicio de este derecho se debe favorecer "la comprensión, la tolerancia y la amistad entre todas las naciones y todos los grupos étnicos o religiosos”. En su numeral 3 consagra el derecho de los padres a elegir la educación que deseen para sus hijos.

Desde sus inicios no se dudó sobre la obligatoriedad moral de La Declaración. Sin embargo, esta obligatoriedad fue más allá, aun cuando su valor jurídico no fuera reconocido de manera directa ${ }^{24}$. Actualmente, en el Derecho internacional como en los derechos estatales, no se cuestiona la fuerza obligatoria que tiene la Declaración, adquirida por vía de incorporarla en las leyes fundamentales de los Estados ${ }^{25}$ así como por la aplicación y referencia permanente que han hecho de ella los órganos de las Naciones Unidas $^{26}$.

Se estima que la relevancia de este instrumento en materia de libertad religiosa radica en ser la base para el tratamiento de esta libertad en los instrumentos internacionales posteriores ${ }^{27}$.

\section{La Declaración sobre eliminación de todas las formas de intolerancia y discriminación fundadas en la religión o las convicciones}

En esta declaración, proclamada por la Asamblea General de las Naciones Unidas el 25 de noviembre de 1981, mediante resolución 36/55 [A/RES/36/55] la libertad

\footnotetext{
23 CORTÍNEZ (1995) p. 35.

${ }^{24}$ TRUYOL (1984) pp. 29-32; CANÇADO (2001) pp. 61-63; URIOS (1993) pp. 93-94.

25 Robertson (1972) pp. 25-28. A modo de ejemplo: El artículo 10 No 2 de la Constitución española recoge expresamente la Declaración Universal de Derechos Humanos: "Las normas relativas a los derechos fundamentales y a las libertades que la Constitución reconoce, se interpretarán de conformidad con la Declaración Universal de Derechos Humanos y los tratados y acuerdos internacionales sobre las mismas materias ratificados por España”; artículo 75 No 22 párrafo segundo de la Constitución argentina, señala igualmente de manera expresa que la Declaración Universal de Derechos Humanos (entre otros instrumentos) tiene jerarquía constitucional; la Constitución francesa en su preámbulo señala su "adhesión a los derechos humanos"; en nuestra Carta fundamental, en el Capítulo I que contiene las Bases de nuestra institucionalidad, el artículo $1^{\circ}$ inciso 1 señala " las personas nacen libres e iguales en dignidad y derechos" y por su parte el artículo $5^{\circ}$ inciso 2 expresa "El ejercicio de la soberanía reconoce como limitación el respeto a los derechos esenciales que emanan de la naturaleza humana".

${ }^{26}$ FRÜHLING (1990) p. 35; ViLLÁN (2001) pp. 51-77.

27 SALINAS (2004) p. 140 .
} 
religiosa "es objeto de atención directa y detallada" 28 . El gran mérito de este instrumento internacional radica en sus esfuerzos por precisar el contenido de la libertad religiosa haciendo una enumeración no taxativa ${ }^{29}$ de las libertades que contempla este "derecho a la libertad de pensamiento, de conciencia, de religión o de convicciones" ${ }^{30}$. Define lo que debe entenderse por intolerancia y discriminación basada en la religión o las convicciones (art. 2o ${ }^{31}$. Reitera la dignidad de la persona humana como fundamento del derecho a la libertad religiosa en su parte considerativa.

El artículo $3^{\circ}$ es tajante al expresar que la discriminación por razones de religión o convicciones "debe ser condenada como una violación a los derechos humanos y las libertades fundamentales" 32 .

El artículo $5^{\circ}$ de la Declaración se refiere de manera exclusiva al derecho del niño en materia de libertad religiosa, estableciendo: el derecho de los padres o tutores legales en su caso de educarlo en la religión o convicciones que deseen $\left(\mathrm{n}^{\circ} 1\right)$; el derecho del niño a tener acceso a educación en materia de religión de acuerdo a lo que sus padres o tutores legales deseen y no se puede obligar al niño a educarse en materia de religión o convicciones que contradiga los deseos de aquellos $\left(n^{\circ} 2\right)$ y si el niño no está bajo el cuidado de sus padres o tutores legales tendrá derecho a que se respete la decisión de estos en materia de religión y su instrucción $\left(\mathrm{n}^{\circ} 4\right)$.

Consideramos que, atendido el numeral 2 de este artículo $5^{\circ 33}$, el Estado tiene el deber de permitir que el niño sea educado en la religión que sus padres o tutores legales eligieron y que si el Estado no puede proporcionar directamente esta educación, será a través de los particulares que se podrá cumplir con este derecho de acceso a educación en materia religiosa.

\section{Declaración sobre los derechos de las personas pertenecientes a minorias nacionales o étnicas, religiosas y lingüisticas}

Esta Declaración, aprobada por la Asamblea General en su resolución 47/135 del 18 de diciembre de $1992^{34}$, a nuestro juicio cabe también considerarla entre aquellas

\footnotetext{
28 SALINAS (2004) p. 142.

29 SALinas (2004) p. 142.

30 Art. $6^{\circ}$ de la Declaración sobre eliminación de todas las formas de intolerancia y discriminación fundadas en la religión o las convicciones ver en http://daccessdds.un.org/doc/RESOLUTION/GEN/ NR0/414/16/IMG/NR041416.pdf?OpenElement [fecha de consulta: 30 de enero de 2008].

31 CorTínez (1995) p. 40-42.

32 Declaración sobre eliminación de todas las formas de intolerancia y discriminación fundadas en la religión o las convicciones. [A/ RES/36/55] consultada en http://daccessdds.un.org/doc/RESOLUTION/ GEN/NR0/414/16/IMG/NR041416.pdf?OpenElement [fecha de consulta: 30 de enero de 2008].

33 Art. $5^{\circ}$ número 2 de la Declaración sobre eliminación de todas las formas de intolerancia y discriminación fundadas en la religión o las convicciones: "Todo niño gozará del derecho a tener acceso a educación en materia de religión o convicciones conforme con los deseos de sus padres o, en su caso, sus tutores legales, y no se le obligará a instruirse en una religión o convicciones contra los deseos de sus padres o tutores legales, sirviendo de principio rector el interés superior del niño". Consultado en http://daccessdds.un.org/doc/RESOLUTION/ GEN/NR0/414/16/IMG/NR041416.pdf?OpenElement [fecha de consulta: 30 de enero de 2008].

34 Consultada en http://daccessdds.un.org/doc/RESOLUTION/GEN/NR0/031/65/IMG/ NR003165.pdf?OpenElement. [fecha de consulta: 29 de enero de 2008].
} 
cuya particular atención es el derecho a la libertad religiosa de personas pertenecientes a minorías religiosas (valga aquí la redundancia).

En su artículo primero se declara como deber de los Estados proteger la existencia de estas minorías y la obligación de fomentar las condiciones para la promoción de su propia identidad. Se les exige a los Estados la adopción de medidas legislativas y de otro tipo para cumplir con los objetivos que pretende la Declaración ${ }^{35}$.

Recalca esta Declaración que las personas pertenecientes a minorías religiosas tienen derecho a profesar y practicar su propia religión, derecho que puede ser ejercido en público o en privado. Se les reconoce también a estas minorías religiosas el derecho a formar y mantener sus propias asociaciones ${ }^{36}$.

\section{Valor vinculante de estas declaraciones para los Estados}

Estas denominadas "declaraciones" adoptadas por la Asamblea General de las Naciones Unidas, nacen de resoluciones que aquella emite en las que se "establecen normas de conducta generales y abstracta, dirigidas a los Estados"37, que son los mismos Estados integrantes de la Asamblea General. Su efecto jurídico vinculante, con algunas excepciones como la Declaración Universal de los Derechos humanos a la que ya nos hemos referido, es cuestión discutida en la doctrina ${ }^{38}$.

Sin exponer con mayor profundidad el tema -pues no es objetivo de este trabajonos manifestamos en el sentido de atribuirles (a las declaraciones) algo más que una mera obligación moral para los Estados miembros de las Naciones Unidas, quienes han sido autores directos de la resoluciones que aprueban estas declaraciones, por lo que nos adscribimos a aquellos que consideran que los Estados no pueden actuar desvinculados del contenido de ellas ${ }^{39}$.

No podemos olvidar la influencia de algunas resoluciones de las organizaciones internacionales en la formación de la costumbre internacional ${ }^{40}$. La Corte Internacional de Justicia (CIJ) órgano jurisdiccional de las Naciones Unidas, en el caso relativo a las actividades militares y paramilitares en Nicaragua y contra Nicaragua (Nicaragua contra los Estados Unidos de América) a este respecto dijo: “(...) La Corte considera que esa opinio iuris podía deducirse, en particular de la actitud de las partes y de otros estados

\footnotetext{
35 Art. 1 “1. Los Estados protegerán la existencia y la identidad nacional o étnica, cultural, religiosa y lingüística de las minorías dentro de sus territorios respectivos y fomentarán las condiciones para la promoción de esa identidad. 2. Los Estados adoptarán medidas apropiadas, legislativas y de otro tipo, para lograr esos objetivos".

36 Art. 2 "1. Las personas pertenecientes a minorías nacionales o étnicas, religiosas y lingüísticas (...) tendrán derecho a disfrutar de su propia cultura, a profesar y practicar su propia religión, (...) en privado y en público, libremente y sin injerencia ni discriminación de ningún tipo. (...) 4. Las personas pertenecientes a minorías tendrán el derecho de establecer y mantener sus propias asociaciones”.

37 MARIÑO (2005) p. 405.

38 MARiÑo (2005) pp. 401-412.

39 BECERRA (2005) pp. 567-587; Sobre el valor vinculante de las resoluciones de las organizaciones internacionales ver también: BOYLE y CHINKIN (2007) pp. 211-216; CARRILlO (1976) pp. 365-385; Gutiérrez (1995) pp. 575-591; MARIÑo (2005) pp. 401-412; Sobrino (2006) pp. 128-146

40 PASTOR (2003) p. 149-154. Ver también al respecto CARRILlo (1985) pp. 124-128; LlanOS (2005) pp. 597-598; MilláN (1990) pp. 121-132.
} 
respecto a ciertas resoluciones de la Asamblea General y en particular a la resolución $2625(\mathrm{XXV}) \ldots "$.. 41.

\section{El Pacto Internacional de Derechos Civiles y Políticos ${ }^{42}$}

El artículo 18 consagra varios aspectos del derecho a la libertad religiosa. En su numeral 1 prescribe: “Toda persona tiene derecho a la libertad de pensamiento, de conciencia y de religión; este derecho incluye la libertad de tener o de adoptar la religión o las creencias de su elección, así como la libertad de manifestar su religión o sus creencias, individual o colectivamente, tanto en público como en privado, mediante el culto, la celebración de los ritos, las prácticas y la enseñanza”. Se consagra así la libertad religiosa en su dimensión individual. No menciona el Pacto nada sobre la dimensión asociativa de esta libertad, por lo que correspondería ubicarla en el artículo 22 que establece el derecho de asociación ${ }^{43}$.

En el inciso $2^{\circ}$, el artículo 18 se refiere a la ausencia de coacción para “....adoptar la religión o creencias de su elección" (igualmente consagrado en la Declaración Universal de Derechos Humanos). Esta ausencia de coacción ha sido entendida por la doctrina que comprende violencia física o amenazas de ella; presión sicológica y también la oferta de beneficios materiales ${ }^{44}$.

Si bien este Pacto replica lo dicho en la Declaración Universal de Derechos $\mathrm{Hu}-$ $\operatorname{manos}^{45}$, no es menos cierto que su tratamiento es más acabado, lo que nos permite afirmar que las normas sobre libertad religiosa incorporadas en este Pacto son de mayor extensión y cabalidad que aquel instrumento ${ }^{46}$.

La Observación General 22 del Comité de Derechos Humanos ${ }^{47}$ sobre el artículo 18 del Pacto ha señalado que, "el derecho a la libertad de pensamiento, de conciencia y

41 "Caso relativo a las actividades militares y paramilitares en Nicaragua y contra Nicaragua (Nicaragua contra los Estados Unidos de América) Fondo del asunto. párrafos 87 a 201 ” en http://www.icj-cij.org/ homepage/sp/files/sum_1948-1991.pdf; En el mismo caso y el mismo sentido respecto a la resolución de la Asamblea General 3314 (XXIX) que define la agresión; y lo mismo respecto de la resolución de la Asamblea General 1803 (XVII) en un fallo arbitral de 12 de enero de 1977: "Texaco-Calasiatic contra Gobierno de Libia”, ver PASTOR (2003) pp. 152-153.

42 La Asamblea General de las Naciones Unidas, por resolución No 2200, adoptada en su XXI Período de Sesiones aprobó el Pacto de Derechos Civiles y Políticos, con fecha 16 de diciembre de 1966, vigente desde el 23 de marzo de 1976. Suscrito por el Estado de Chile en la misma fecha de su aprobación por la Asamblea General, ratificado el 10 de febrero de 1972 y publicado en el Diario Oficial el 29 de abril de 1989.

43 CORTínez (1995) pp. 36-37.

${ }^{44}$ PRECHT (2006) p. 24.

${ }^{45}$ SALINAS (2004) p. 141. Ver artículo 6o de la Declaración.

46 SALiNAS (2004) pp. 235-236.

47 Observación General No 22: Derecho a la libertad de pensamiento, de conciencia y de religión (art. 18) 30/07/93 consultada en www.unhchr.ch/tbs/doc.nsf [fecha de consulta: 27 de noviembre de 2007]. El artículo 28 del Pacto Internacional de Derechos Civiles Políticos establece un Comité de Derechos Humanos cuya principal función es supervisar la aplicación del Pacto y sus protocolos adicionales por parte de los Estados que han ratificado tales acuerdos. El Protocolo Facultativo de este Pacto (CCPR-OP1) reconoce competencia al Comité de Derechos Humanos para conocer de violaciones a los derechos establecidos en aquel. Chile ratificó este Protocolo con fecha 28 de mayo de 1992 y fue publicado en el Diario Oficial el 20 de agosto de 1992. 
de religión (que incluye la libertad de tener creencias) en el párrafo 1 del artículo 18 es profundo y de largo alcance; abarca la libertad de pensamiento sobre todas las cuestiones, las convicciones personales y el compromiso con la religión o las creencias, ya se manifiesten a título individual o en comunidad con otras personas" y agrega más adelante, "El carácter fundamental de estas libertades se refleja también en el hecho de que, como se proclama en el párrafo 2 del artículo 4 del Pacto, esta disposición no puede ser objeto de suspensión en situaciones excepcionales".

En efecto, el Pacto señala que los Estados Partes, en situaciones excepcionales, que pongan en peligro la vida de la nación y previa declaración oficial, podrán suspender las obligaciones que de él emanan, pero excluye de este derecho de suspensión inter alia el artículo 18 , que consagra la libertad religiosa ${ }^{48}$.

Asimismo el Pacto consagra la igualdad ante la ley y el derecho a no ser discriminado en razón de la religión ${ }^{49}$. También consagra expresamente el derecho de las minorías, ya sean "étnicas, religiosas o lingüísticas" a manifestarse acorde a su etnia, a su religión o utilizar su propio idioma. Los Estados se obligan a no negar estos derechos ${ }^{50}$.

El Comité de Derechos Humanos en su Observación General No 22 comunica a los Estados Partes su deseo de ser informado de "las medidas adoptadas por los Estados Partes interesados para proteger la práctica de todas las religiones o creencias de abusos inadmisibles y proteger a sus seguidores de la discriminación”.

Finalmente, pero no menos relevante, el artículo 24 numeral 1 reconoce como derecho del niño, el derecho a no ser discriminado entre otras razones, por motivos de religión.

No hay cuestión sobre la obligatoriedad del Pacto y el Protocolo Facultativo 1 para el Estado de Chile, pues estamos frente a una obligación convencional, válida tanto en el ámbito internacional como en el ámbito interno. Ambos instrumentos han sido incorporados a nuestro ordenamiento jurídico ${ }^{51}$.

En nuestra Constitución Política, el artículo 19 numeral $6^{\circ}$, asegura a todas las personas: "La libertad de conciencia, la manifestación de todas las creencias y el ejercicio libre de todos los cultos"; a su vez el Pacto (al igual que la Declaración Universal de Derechos Humanos) consagra la "libertad de pensamiento, de conciencia y de religión" (art. 18 inc. $1^{\circ}$ del Pacto Internacional de Derechos Civiles y Políticos).

La doctrina nacional ha expresado que la libertad de conciencia, consagrada en nuestra Carta, debe entenderse en un sentido amplio (considera esta postura que la libertad de conciencia tiene como antecedente la libertad de pensamiento necesariamente $)^{52}$. Lo anterior es coincidente con lo expresado por el Comité de Derechos Humanos en la Observación General N ${ }^{\circ} 22$ (ver supra). En cuanto a los otros derechos contenidos en el art. 19 numeral $6^{\circ}$ de nuestra Constitución: “a manifestar todas las creencias” y el

\footnotetext{
48 Art. 4 números 1 y 2 del Pacto Internacional de Derechos Civiles y Políticos.

${ }^{49}$ Art. 26 del Pacto Internacional de Derechos Civiles y Políticos.

${ }^{50}$ Art. 27 del Pacto Internacional de Derechos Civiles y Políticos.

51 Ver notas 42.

52 Evans (1999) pp. 260-262; SiLVA (2006) pp. 234-240.
} 
"ejercicio libre de todos los cultos", estimamos que si bien no han sido enriquecidos sustancialmente por el inciso $1^{\circ}$ del artículo 18 del Pacto, el reconocimiento de estos derechos en un instrumento internacional de la envergadura del Pacto, no viene sino a reforzar la existencia de la libertad religiosa como un derecho humano independiente que merece protección específica ${ }^{53}$.

Por otra parte, estimamos, que el inciso $2^{\circ}$ del artículo 18 contribuiría a enriquecer la normativa constitucional en cuanto -expresamente- se establece el derecho a no ser coaccionado para adoptar libremente una religión o creencia determinada ${ }^{54}$.

Sin duda, un elemento destacable en la contribución que puede hacer el Pacto al derecho a la libertad religiosa en nuestro ordenamiento jurídico, dice relación con la debida protección de este derecho. Así el artículo 2 inciso $3^{\circ}$, en el que se consagran obligaciones para los Estados Partes, señala expresamente: "Cada uno de los Estados Partes en el presente Pacto se compromete a garantizar que: a) Toda persona cuyos derechos o libertades reconocidos en el presente Pacto hayan sido violados podrá interponer un recurso efectivo, aun cuando tal violación hubiera sido cometida por personas que actuaban en ejercicio de sus funciones oficiales" 55 .

La idea del recurso efectivo es determinante en la protección de los derechos humanos para el Derecho Internacional. Si bien el Comité de Derechos Humanos no ha realizado un General Comments sobre el derecho a un recurso efectivo (contenido en el art. 2 inciso $3^{\circ}$ letra a) sí lo han hecho dos órganos jurisdiccionales de radical importancia en el desarrollo de la protección de los derechos humanos. La Corte Interamericana de Derechos Humanos ha expresado que no basta la existencia del recurso sino que este debe ser "capaz de producir el resultado para el que ha sido concebido" 56 . Por su parte

53 Silva (2006) pp. 232-233 y 241.

54 Ver al respecto el debate producido en la Comisión de Estudios de la Nueva Constitución (Comisión Ortúzar) en la Sesión 130, de 17 de junio de 1975. Esta Sesión se encuentra transcrita en las páginas 265 a 291 en el texto de Evans DE LA CuADra: "Los Derechos constitucionales" Tomo I (ver bibliografía citada al final de este artículo). Sobre el particular ver la página 281, donde queda expuesto que para la Comisión Ortúzar se entiende incluido este derecho, a no ser obligado a profesar una religión, en la forma en que está contemplado en el artículo 19 numero $6^{\circ}$ de la Constitución en concordancia con la igualdad ante la ley también consagrada en nuestra Carta.

55 El art. 13 del Convenio Europeo para la protección de los Derechos Humanos y de las Libertades Fundamentales (Convenio Europeo de Derechos Humanos) establece en términos similares el derecho a este recurso efectivo. Consultado en: http://www.echr.coe.int/NR/rdonlyres/1101E77A-C8E1-493F809D-800CBD20E595/0/SpanishEspagnol.pdf [fecha de consulta: 11 de febrero de 2008]; el mismo derecho a un recurso efectivo está contemplado en el artículo 25 inciso 1 de la Convención Americana sobre Derechos Humanos. Consultado en Documentos básicos en materia de derechos humanos en el Sistema Interamericano (actualizado a enero de 2005). Una publicación de la Secretaría General de la Organización de los Estados Americanos Washington D.C. 2005.

${ }^{56}$ Caso Velásquez Rodríguez contra Honduras. Sentencia de Fondo de 29 de julio de 1988, Párrafo 66 (ver también párrafo 63) consultado en http://www.corteidh.or.cr/docs/casos/articulos/seriec_04_esp.pdf [fecha de consulta: 11 de febrero de 2008]. Lo mismo ha reiterado la Corte en varias de sus sentencias, como una muestra de ello ver: Caso Maritza Urrutia contra Guatemala. Sentencia de 27 de noviembre de 2003 párrafo 117 consultado en http://www.corteidh.or.cr/docs/casos/articulos/seriec_103_esp.pdf [fecha de consulta: 11 de febrero de 2008] Caso Tibi contra Ecuador. Sentencia de 7 de septiembre de 2004, párrafos 130 y 131 consultado en http://www.corteidh.or.cr/docs/casos/articulos/seriec_114_esp.pdf [fecha de consulta: 11 de febrero de 2008]. 
el Tribunal Europeo de Derechos Humanos también se ha pronunciado al respecto 57 .

\section{El Pacto Internacional de Derechos Económicos Sociales y culturales ${ }^{58}$}

No se hace aquí una mención especial a la libertad religiosa como la contenida en el Pacto Internacional de Derechos Civiles y Políticos. Su mención es en relación con el derecho a la educación ${ }^{59}$.

El artículo 13 párrafo 1 señala que la educación debe "favorecer la comprensión, la tolerancia y la amistad entre todas las naciones y entre todos los grupos raciales, étnicos o religiosos". Ha sido destacado por los órganos de las Naciones Unidas -al definir el contenido normativo del párrafo 1 del artículo 13- la comunidad de objetivos entre este y el párrafo 2 del artículo 26 de la Declaración Universal de Derechos Humanos, expresando concretamente, el Comité de Derechos Económicos, Sociales y Culturales como un objetivo fundamental, entre los comunes a ambos instrumentos, el que afirma que "la educación debe orientarse hacia el desarrollo del sentido de la dignidad de la personalidad humana" 60 .

A nuestro juicio este objetivo destacado como fundamental por el Comité contiene la idea de que la educación debe favorecer la comprensión entre los grupos "raciales étnicos o religiosos" (art.13 $\mathrm{n}^{\circ} 1$ ); el derecho de los padres a educar a sus hijos conforme a sus convicciones religiosas (art.13 $\mathrm{n}^{\circ} 3$ ); derecho a escoger escuelas distintas de las públicas (art.13 $\mathrm{n}^{\circ} 3$ ) y el derecho de los particulares y entidades para establecer y dirigir escuelas conforme a sus convicciones (art. $13 n^{\circ} 4$ ). No cabe duda que todos estos derechos que son contenidos de la libertad religiosa y expuestos en el derecho a la educación están construidos teniendo como base la dignidad de la persona humana.

\section{Los Convenios de Ginebra de 1949}

Estos cuatro convenios merecen ser mencionados pues, aun cuando no exista un tratamiento como los contenidos en los pactos internacionales o en las declaraciones ya descritas, revelan la importancia que se ha dado por parte del Derecho internacional al derecho a la libertad religiosa.

57 Terol et al. (2005) pp. 170-172. En estas páginas aparece citado el caso Klass y otros c. R.F. de Alemania. STEDH de 6 de septiembre de 1978, Serie A n ${ }^{\circ} 28$.

${ }^{58}$ Ratificado por Chile el 10 de febrero de 1972 y publicado en el Diario Oficial el 27 de mayo de 1989.

59 SALinas (2004) p. 235.

${ }^{60}$ El derecho a la educación (art.13) 8/12/99. E/C.12/1999/10. (General Comments). Comité de Derechos Económicos, Sociales y Culturales, $21^{\text {er }}$ período de sesiones, 15 de noviembre a 3 de diciembre de 1999. Aplicación del Pacto Internacional de Derechos Económicos, Sociales y Culturales. Observaciones Generales 13 (ver especialmente los párrafos 4, 5, 28, 29 y 30).

El Comité de Derechos Económicos, Sociales y Culturales fue establecido por resolución 1985/17 del Consejo Económico y Social de las Naciones Unidas con fecha 28 de mayo de 1985. Este Comité tiene a su cargo las funciones de supervigilancia contenidas en el párrafo IV del Pacto Internacional de Derechos Económicos Sociales y Culturales [Fuente: www.ohchr.org]. 
En los Convenios (I y II) se establece la no discriminación en razón de la religión para el trato que se les debe dar a los heridos y enfermos de las fuerzas armadas en campaña y los náufragos de las fuerzas armadas en el mar ${ }^{61}$.

Por su parte en el Convenio (III) ${ }^{62}$ establece normas respecto al personal religioso retenido para asistir a los prisioneros de guerra (art. 33) y el artículo 34 les otorga (a los prisioneros de guerra) plena libertad para el ejercicio de su religión incluyendo la asistencia a los actos de culto, solo bajo condición de que no sean incompatibles con la normas disciplinarias "normales" garantizando incluso que se tengan "locales adecuados" para los actos religiosos. El artículo 120 establece, además, que se deben respetar los ritos de entierro de la religión de los prisioneros fallecidos.

Finalmente el Convenio (IV) ${ }^{63}$ que protege a los civiles en tiempos de guerra, establece la no discriminación en el trato a los civiles y a la población en general en razón de la religión (arts. 3 y 13). El artículo 24 señala que a los menores de 15 años huérfanos o separados de su familia con ocasión de la guerra se les debe procurar la práctica de su religión. Establece además que si estos menores son evacuados a un país neutral, debe cuidarse el respeto a las garantías establecidas, entre las cuales está la práctica de su religión. El artículo 38 reconoce el derecho (a los civiles) a practicar su religión y a recibir asistencia espiritual por parte de sus ministros de culto. El art. 58 establece que para el caso de territorios ocupados, se debe permitir la asistencia espiritual por parte de los ministros de los diversos cultos a sus correligionarios y también debe aceptar la potencia ocupante el envío y distribución de libros y otros objetos de índole religiosa.

El Capítulo V de la sección IV, denominado "Religión actividades intelectuales y físicas" consagra el derecho al ejercicio de su religión y respecto a los internados que sean ministros de culto consagra el derecho a ejercer su ministerio, incluso permite que les sea proporcionado si no existe entre los internados un ministro de culto o bien son insuficientes para asistir a todos los que lo necesitan. El artículo 130 por su parte consagra similar derecho a los internados que aquel establecido en el artículo 120 del III Convenio ${ }^{64}$.

\section{Convención sobre los Derechos del Niño65}

El artículo 2 no 1 genera a los Estados partes, la obligación de respetar y garantizar el cumplimiento de los derechos enunciados sin discriminación en razón de la

\footnotetext{
${ }^{61}$ Convenio de Ginebra para aliviar la suerte que corren los heridos y los enfermos de las fuerzas armadas en campaña (Convenio I) y Convenio de Ginebra para aliviar la suerte que corren los heridos, los enfermos y los náufragos de las fuerzas armadas en el mar (Convenio II). Ambos convenios están vigentes desde el 21 de octubre de 1950. Ratificados por Chile ese mismo año y publicados en el Diario Oficial en abril de 1951.

${ }^{62}$ Convenio de Ginebra relativo al trato debido a los prisioneros de guerra (Convenio III) ratificado por Chile el 12 de octubre de 1950 y publicado en el Diario Oficial el 18 de abril de 1951.

${ }^{63}$ Convenio de Ginebra relativo a la protección debida a las personas civiles en tiempo de guerra (Convenio IV) ratificado por Chile el 12 de octubre de 1950 y publicado en el Diario Oficial el 19 y 20 de abril de 1951.

64 ver artículo 68 del IV Convenio para efectos de lo que se entiende por "internados".

65 Adoptada por la Asamblea General de las Naciones Unidas el 20 de noviembre de 1989, entró en vigor el 2 de septiembre de 1990. Ratificada por Chile el 13 de agosto de 1990 y publicada en el Diario Oficial el 27 de septiembre de ese mismo año. [Fuente: Ministerio de Relaciones Exteriores, Dirección de Derechos Humanos].
} 
religión (entre otras causas) y el $\mathrm{n}^{\circ} 2$ establece la obligación de los Estados partes de garantizar que el niño sea protegido contra toda forma de discriminación o castigo, inter alia, por "las creencias de sus padres, sus tutores o de sus familiares" 66.

El artículo 14 no 1 consagra el derecho del niño a que el Estado respete su "derecho a la libertad de pensamiento, conciencia y religión" y el numeral 2 establece la obligación para los Estados partes de respetar el derecho y el deber de los padres o de los representantes legales, si fuere el caso, "de guiar al niño en el ejercicio de su derecho, de modo conforme a la evolución de sus facultades"67. Igual norma está contemplada en el artículo $5^{\circ}$ de la Convención, referida a todos los derechos reconocidos al niño.

Creemos que estas obligaciones se corresponden con lo establecido en el artículo $5^{\circ}$ de la Declaración sobre eliminación de todas las formas de intolerancia y discriminación fundadas en la religión o las convicciones (ver supra acápite A) 2.) que consagra el derecho de los padres a educar a sus hijos en la religión o creencia que estos elijan y por otro lado el derecho del niño a tener acceso a educación en materia de religión o convicciones de acuerdo a lo que sus padres deseen, siempre teniendo presente el "interés superior del niño" tal como ocurre en la Convención sobre los Derechos del Niño. Lo anterior, postulamos igualmente, está en concordancia con el artículo $13 \mathrm{n}^{\circ} 3$ del Pacto Internacional de Derechos Económicos Sociales y Culturales (ver supra acápite A) 6.).

La Convención no establece el contenido de las libertades consagradas en el art. 14 , por lo que entendemos que habría que recurrir a otros instrumentos internacionales para definir su contenido.

El artículo 29 n 1 consagra en materia del derecho a la educación, que esta debe ser encaminada hacia la tolerancia de la diversidad y el respeto a los grupos religiosos y en el numeral 2 reconoce el derecho a "los particulares y las entidades a establecer y dirigir instituciones de enseñanza”. Estimamos que con ello se reconoce el derecho de las congregaciones religiosas a ejercer este derecho (valga aquí la redundancia).

Esta Convención también contempla un órgano que vigila el cumplimiento por parte de los Estados de las obligaciones de respetar y garantizar la aplicación de los derechos contenidos en ella. Este Comité se ha pronunciado respecto del artículo 29 en la Observación general No $1^{68}$, pero no ha hecho una mención especial sobre el derecho a la libertad religiosa y su contenido.

\section{B) INSTRUMENTOS DE CARÁCTER REGIONAL}

\section{La Declaración Americana de los Derechos y Deberes del Hombre}

Formulada con anterioridad a la Declaración Universal, el 2 de mayo de 1948, el artículo III establece que "toda persona tiene el derecho de profesar libremente una

\footnotetext{
66 Art. $2 \mathrm{n}^{\circ} 2$ de la Convención sobre los Derechos del Niño. Consultado en http://www.unhchr.ch/ spanish/html/menu3/b/k2crc_sp.htm [fecha de consulta: 11 de febrero de 2008].

67 Art. $14 \mathrm{n}^{\circ} 2$ de la Convención sobre los Derechos del Niño. Consultado en http://www.unhchr.ch/ spanish/html/menu3/b/k2crc_sp.htm [fecha de consulta: 11 de febrero de 2008].

68 Observación general No 1 Propósitos de la educación, realizada en el 26º período de sesiones del Comité [fuente: http://www.unhchr.ch/tbs/doc.nsf/(Symbol)/HRI.GEN.1.Rev.7.Sp?Opendocument]
} 
creencia religiosa y de manifestarla y practicarla en público y en privado”, consagrando así la libertad religiosa en su dimensión individual ${ }^{69}$. La dimensión colectiva queda protegida a nuestro juicio por el artículo XXII que permite la expresión pública de los intereses religiosos en asociación con otros ("promover" dice la Declaración).

Respecto de este instrumento internacional estimamos que constituye algo más que un valor moral para los Estados que la suscribieron y que son parte de la Organización de Estados Americanos $(\mathrm{OEA})^{70}$. Al respecto, la Corte Interamericana de Derechos Humanos, en uso de su competencia consultiva, se ha pronunciado sobre el valor jurídico de esta Declaración y ha dicho: "Para los Estados Miembros de la Organización ${ }^{71}$, la Declaración es el texto que determina cuáles son los derechos humanos a que se refiere la Carta (...) para estos Estados la Declaración Americana constituye, en lo pertinente y en relación con la Carta de la Organización, una fuente de obligaciones internacionales"72. Cobra relevancia lo anterior por cuanto no todos los Estados americanos son parte de la Convención Americana de Derechos Humanos pero sí lo son de la Organización de Estados Americanos ${ }^{73}$.

\section{La Convención Americana sobre derechos humanos o Pacto de San José de Costa Rica ${ }^{74}$}

Esta Convención (o Pacto, en adelante) vigente desde el 18 de julio de 1978, consagra de manera expresa en su artículo 12 la libertad de conciencia y de religión ${ }^{75}$, en cuanto a su contenido no difiere de lo establecido en el artículo 18 del Pacto Internacio-

${ }^{69}$ CORTÍNEZ (1995) p. 39.

70 SAlVIOLI (1999) p. 26; FIX (1998) p. 97.

71 Se refiere a la Organización de Estados Americanos (OEA).

72 Opinión consultiva OC-10/89 del 14 de julio de 1989. El artículo 29 de la Convención Americana sobre Derechos Humanos, señala que "Ninguna disposición de la presente Convención puede ser interpretada en el sentido de: letra d) excluir o limitar el efecto que puedan producir la Declaración Americana de Derechos y Deberes del Hombre y otros actos internacionales de la misma naturaleza”.

73 No han suscrito ni ratificado la Convención Americana sobre Derechos Humanos, Antigua y Barbuda; Bahamas; Belice; Canadá; Cuba (su actual Gobierno, mediante resolución de la Octava reunión de Consulta de Ministros de Relaciones Exteriores [1962] ha sido excluido de participar en la OEA) Guyana; San Kitts y Nevis; Santa Lucía y St. Vicente \& Grenadines. Estados Unidos suscribió la Convención pero aún no la ratifica (fuente: www.oas.org).

74 Adoptada en la Conferencia especializada interamericana sobre derechos humanos el 22 de noviembre de 1969 en San José de Costa Rica. Suscrita por Chile en esa misma fecha, ratificada el 10 de agosto de 1990 y publicada en el Diario Oficial el 5 de enero de 1991. Al momento de su ratificación Chile declaró reconocer la competencia de la Corte Interamericana de Derechos Humanos (fuente: www.oas.org).

75 Convención Americana de Derechos Humanos "artículo 12. Libertad de Conciencia y de Religión 1. Toda persona tiene derecho a la libertad de conciencia y de religión. Este derecho implica la libertad de conservar su religión o sus creencias, o de cambiar de religión o de creencias, así como la libertad de profesar y divulgar su religión o sus creencias, individual o colectivamente, tanto en público como en privado; 2. Nadie puede ser objeto de medidas restrictivas que puedan menoscabar la libertad de conservar su religión o sus creencias o de cambiar de religión o de creencias; 3. La libertad de manifestar la propia religión y las propias creencias está sujeta únicamente a las limitaciones prescritas por la ley y que sean necesarias para proteger la seguridad, el orden, la salud la moral públicos o los derechos o libertades de los demás y 4. Los padres, y en su caso los tutores, tienen derecho a que sus hijos o pupilos reciban la educación religiosa y moral que esté de acuerdo con sus propias convicciones”. 
nal de Derechos Civiles y Políticos ${ }^{76}$, ni tampoco lo hace de lo dispuesto en nuestra Constitución ni en la ley 19.63877, 78. Estimamos que su importancia radica en la existencia de un órgano de control del Pacto de carácter jurisdiccional, la Corte Interamericana de Derechos Humanos a la cual Chile le ha reconocido competencia ${ }^{79}$.

Además el artículo $1^{\circ}$ de la Convención establece la obligación general, para los Estados partes, de respetar los derechos y libertades que consagra la Convención y en su numeral 1 indica que estos derechos se deben a "toda persona (...) sin discriminación alguna por motivos de raza, color, sexo, idioma, religión, opiniones políticas o de cualquiera otra índole”.

Por su parte el artículo $2^{\circ}$ consagra otra obligación para los Estados partes, el deber de adoptar disposiciones de derecho interno cuando no existan o no fueren suficientes para dar plena eficacia a los derechos garantizados en la Convención.

Jurisprudencia y doctrina coinciden en que las obligaciones contenidas en la Parte I de la Convención en la que se encuentran ambas obligaciones generales contenidas en los artículos 1 y 2 son normas autoejecutables (self-executing) lo que permite invocar la Convención ante los tribunales nacionales ${ }^{80}$.

El artículo 27 establece dos cuestiones relevantes en torno a la protección de la libertad religiosa. En efecto, este artículo permite a los Estados partes en la Convención suspender ciertas garantías en casos de estados de emergencia, pero impide que exista discriminación en razón de la religión (entre otros) en las medidas lícitas que se tomen para superar estas emergencias ${ }^{81}$. Asimismo, la doctrina del núcleo duro de derechos ${ }^{82}$ tal como los contemplados en el Convenio Europeo de Derechos Humanos ${ }^{83}$ se repite en la Convención Americana ${ }^{84}$ incluyendo entre aquellos derechos inderogables -que no ad-

\footnotetext{
76 SALinas (2004) p. 238.

77 Ley 19.638 que establece normas sobre la Constitución Jurídica de las Iglesias y Organizaciones Religiosas. Publicada en el Diario Oficial el 14 de octubre de 1999; ver sobre el contenido de esta ley CEA EGAÑA (2004) pp. $210-213$.

78 Nogueira (2006) pp. 13-41.

${ }^{79}$ Los artículos $62 \mathrm{n}^{\circ} 3$ y 64 de la Convención Americana contemplan la facultad de la Corte de conocer casos contenciosos (competencia contenciosa) y de emitir opiniones consultivas (competencia consultiva). De acuerdo a lo establecido en el artículo 62 números 1 y 2 los Estados partes en la Convención pueden reconocer como obligatoria la competencia contenciosa de la Corte. Consultado en: http://www.oas.org/ juridico/spanish/tratados/b-32.html [fecha de consulta: 10 de febrero de 2008].

${ }^{80}$ CANÇADO (2001) pp. 283-285; MEDINA (1990) pp.149-153; RODRÍGUEZ (1994) pp. 460.

81 FIX (1998) pp. 100-101.

82 Carrillo (2003) pp. 31-32.

83 Ver art. 15 del Convenio Europeo para la protección de los derechos humanos y de las libertades fundamentales, también llamado Convenio Europeo de Derechos Humanos. En este Convenio no se contempla entre aquellos derechos inderogables y que no admiten suspensión los consagrados en el artículo 9 (libertad de pensamiento conciencia y religión).

${ }^{84}$ Art. 27 Convención Interamericana de Derechos Humanos: "Suspensión de garantías 1. En caso de guerra, de peligro público o de otra emergencia que amenace la independencia o seguridad del Estado parte, este podrá adoptar disposiciones que, en la medida y por el tiempo estrictamente limitados a las exigencias de la situación, suspendan las obligaciones contraídas en virtud de esta Convención, siempre que tales disposiciones no sean incompatibles con las demás obligaciones que les imponen el derecho internacional y no entrañen discriminación alguna fundada en motivos de raza, color, sexo, idioma, religión u origen social. 2. La disposición precedente no autoriza la suspensión de los derechos determina-
} 
miten suspensión o restricción temporal- los consagrados en el artículo 12, la Libertad de Conciencia y de Religión ${ }^{85}$.

La existencia de dos órganos de control del Pacto ${ }^{86}$ : La Corte Interamericana de Derechos Humanos (en adelante la Corte) y la Comisión Interamericana de Derechos Humanos ${ }^{87}$ (en adelante la Comisión) han permitido un desarrollo progresivo del Derecho Internacional de los Derecho Humanos en el denominado Sistema Interamericano de Protección de los Derechos Humanos, respecto del cual constituyen eje central del mismo la Convención; la Carta de la Organización de los Estados Americanos (OEA) y la Declaración Americana de los Derechos y Deberes del Hombre.

Este desarrollo se ha venido realizando a partir de los pronunciamientos de la Comisión y muy especialmente de la Jurisprudencia de la Corte Interamericana ${ }^{88}$.

En cuanto a la aplicación del artículo 12, y las actuaciones del Estado de Chile, existen dos registros de denuncias ${ }^{89}$ efectuadas ante la Comisión por violación al artículo 12: El caso Cristian Daniel Sahli Vera y otros (iniciado en 1999) en el que se reclamaba por la violación a la libertad de conciencia, por no poder ejercer el derecho a objeción de conciencia frente a la obligación de realizar el servicio militar impuesta por el Estado de Chile. La Comisión se pronunció señalando que el artículo 12 no hace mención explícita al término "objeción de conciencia” y que este término solo es mencionado en la Convención Americana en el artículo 6(3) (b) ${ }^{90}$.

La Comisión declaró que no se había violado el artículo 12 y siguiendo la jurisprudencia internacional tanto de los órganos de Naciones Unidas como del Sistema Europeo de Derechos Humanos expresa en el párrafo 97 de su análisis del fondo del asunto lo siguiente:

"La Comisión lee el artículo 12 (El derecho a la libertad de conciencia conjuntamente con el artículo 6 (3)(b) de la Convención Americana interpretando que reconocen expresamente el derecho a la condición de objetor de conciencia en los

dos en los siguientes artículos: 3 (Derecho al reconocimientote la personalidad jurídica); 4 (Derecho a la vida) (...) 12 (Libertad de conciencia y de religión). (...)”.

85 Medina (1990) pp. 157-158.

86 Artículo 33 de la Convención Americana sobre Derechos Humanos.

${ }^{87}$ La Comisión Interamericana fue creada en la Quinta Reunión de Consulta de Ministros de Relaciones Exteriores, que tuvo lugar en Santiago de Chile en 1959. La Comisión es un órgano de la OEA desde la reforma introducida a dicha Organización Internacional por el Protocolo de Buenos Aires en 1967 y cuya vigencia data de 1970. (ver art. 106 de la Carta de la Organización de los Estados Americanos) Fuente: http://www.cidh.oas.org.

88 CANÇADO y Ventura (2004) p. 15.

${ }^{89}$ Fuente consultada: www.cidh.oas.org la información aparece actualizada al año 2007.

90 Párrafo 37 del Informe sobre el fondo No 43/05 Caso 12.219 Cristian Daniel Sahli Vera y otros contra el Estado de Chile de 10 de marzo de 2005 (ver también párrafos 32 a 100). En esta denuncia ante la Comisión Interamericana de Derechos Humanos los peticionarios invocaron el artículo 12 en relación a la libertad de conciencia (no se refieren a la libertad de religión) y su derecho a objeción de conciencia en el cumplimiento del servicio militar obligatorio. El informe es desfavorable para los peticionarios (fuente: http://www.cidh.oas.org/annualrep/2005sp/CHILE.12219sp.htm). 
países en que dicha condición está reconocida en su legislación interna. En Chile, la condición de objetor de conciencia no está reconocida en las leyes nacionales, por lo cual el Estado argumenta convincentemente que no está obligado a otorgarla, dado que el artículo 12 de la Convención autoriza expresamente al Estado a limitar el ámbito del derecho por razones de seguridad nacional, habiendo así, por tanto, procedido" 91 .

La segunda ocasión en que Chile ha sido denunciado ante la Comisión y posteriormente demandado ante la Corte por violación al artículo 12 de la Convención es en el caso que se suscitó con ocasión de la prohibición de exhibir en el país la película "La última tentación de Cristo" 92 .

Con fecha 15 de enero de 1999, la Comisión presentó la demanda ante la Corte contra el Estado de Chile a objeto de que esta última se pronunciara si el Estado de Chile había violado los artículos 13 (libertad de pensamiento y expresión) y 12 (libertad de conciencia y religión) de la Convención Americana de Derechos Humanos ${ }^{93}$. Este es el primer y único caso que ha conocido la Corte en relación a la libertad de religión, según datos estadísticos emitidos por el mismo tribunal ${ }^{94}$.

En los alegatos presentados por la Comisión (y consignados en la sentencia) respecto al artículo 12 y su contenido la Comisión expresa lo siguiente en su acápite IX párrafo 74:

"b. el reconocimiento a la libertad de conciencia se funda en el reconocimiento mismo del ser humano como ser racional y autónomo. La protección del derecho a esta libertad es la base del pluralismo necesario para la convivencia en una sociedad democrática que, como toda sociedad, se encuentra integrada por individuos de variadas convicciones y creencias".

c. Conforme al artículo 12 de la Convención, "el Estado debe tomar las medidas necesarias y proporcionales para que las personas que profesan públicamente sus creencias conduzcan sus ritos y lleven a cabo sus proselitismos dentro de los límites que razonablemente puedan imponerse en una sociedad democrática”. Esta norma exige abstención estatal de interferir de cualquier modo la adopción, el mantenimiento o el cambio de convicciones personales religiosas o de otro carácter".

\footnotetext{
91 Ver nota 90.

92 Ver informe No 31/98 Juan Pablo Olmedo Bustos y otros Caso 11.803 (Chile) mediante el cual se declara admisible la petición de los demandantes (fuente: http://www.cidh.oas.org/annualrep/98span/Admisibilidad/Chile11.803.htm).

93 Párrafo 1. del caso "La última tentación de Cristo", Olmedo Bustos y otros contra Chile. Fondo, reparaciones y costas. Sentencia de 5 de febrero de 2001 Serie C No 73 en www.corteidh.or.cr.

${ }^{94}$ Informe anual de la Corte Interamericana de Derechos Humanos, Año 2006 p.88. Disponible en: http:/ /www.corteidh.or.cr/informes.cfm [fecha de consulta: 21 de noviembre de 2007].
} 
La Corte no acogió la demanda de la Comisión en cuanto a la violación por parte de Chile al artículo 12 y entrega el núcleo central de sus argumentos en el párrafo 79 de su sentencia:

"Según el artículo 12 de la Convención, el derecho a la libertad de conciencia y de religión permite que las personas conserven, cambien, profesen y divulguen su religión o sus creencias. Este derecho es uno de los cimientos de la sociedad democrática. En su dimensión religiosa, constituye un elemento trascendental en la protección de las convicciones de los creyentes y en su forma de vida. En el presente caso sin embargo, no existe prueba alguna que acredite la violación de ninguna de las libertades consagradas en el artículo 12 de la Convención. En efecto, entiende la Corte que la prohibición de la exhibición de la película 'La última tentación de Cristo’ no privó o menoscabó a ninguna persona su derecho de conservar, cambiar, profesar o divulgar, con absoluta libertad, su religión o sus creencias".

La Corte no hace un análisis del contenido de la libertad religiosa, sin embargo opinamos que hay dos cuestiones de relevancia que los Estados deben considerar en el pronunciamiento de la Corte (y en su caso también de la Comisión) por una parte, el reconocimiento que hacen ambos órganos (Corte y Comisión) de lo fundamental de este derecho a la libertad religiosa, definiéndolo como "uno de los cimientos de la sociedad democrática”, y por otra, la Corte enfatiza la importancia de este derecho al señalar que "en su dimensión religiosa, constituye un elemento trascendental en la protección de las convicciones de los creyentes y en su forma de vida" $"$.

Es oportuno mencionar que en cuanto al derecho que la Corte Interamericana puede aplicar cuando conoce de algún asunto contencioso, la propia Corte ha ido más allá del artículo $62 \mathrm{n}^{\mathrm{0}} 3^{96}$ y ha recurrido a la idea del "comprensivo corpus iuris internacional" 97, esto es "la utilización de otras normas del derecho internacional o del derecho internacional de los derechos humanos" para "informar las normas de la Convención"98.

\footnotetext{
${ }^{95}$ NOGUeiRA (2006) pp. 13-41, destaca ambas ideas.

${ }^{6}$ Artículo 62 no 3 "La Corte tiene competencia para conocer de cualquier caso relativo a la interpretación y aplicación de las disposiciones de esta Convención que le sea sometido...".

97 Caso de los "Niños de la calle" (Villagrán Morales y Otros). Sentencia de 19 de noviembre de 1999. Serie C, no 63 [fuente: http://www.corteidh.or.cr/casos.cfm ] en el párrafo 194 la Corte señala: "Tanto la Convención Americana como la Convención sobre los Derechos del Niño forman parte de un muy comprensivo corpus juris internacional de protección de los niños que debe servir a esta Corte para fijar el contenido y los alcances de la disposición general definida en el artículo 19 de la Convención Americana". Ver también los casos: Castillo Petruzzi y otros contra Perú, Sentencia de 20 de mayo de 1999, párrafo 139; Tribunal Constitucional contra Perú, sentencia de 31 de enero de 2001 párrafos 73 y 74; Juan Humberto Sánchez contra Honduras Sentencia de 7 de junio de 2003 párrafo 127. En todos estos casos la Corte utiliza otros instrumentos tales como Declaraciones para informar su interpretación de las normas de la Convención.

${ }^{98}$ MARTIN (2004) p. 229.
} 
Es así como la Corte ha utilizado la Jurisprudencia del Tribunal Europeo de Derechos Humanos ${ }^{99}$ y del Comité de Derechos Humanos ${ }^{100}$ para fundamentar sus sentencias aun cuando aquella no tiene efecto vinculante. Con este escenario, entonces, deberíamos conocer particularmente los fallos en que se ha alegado violación al derecho a la libertad religiosa del Convenio Europeo de Derechos Humanos ${ }^{101}$, por cuanto a diferencia de lo que ha ocurrido en la Corte Interamericana el Tribunal Europeo de Derechos Humanos se ha pronunciado en varias ocasiones por violación al artículo 9, aun cuando mirado en el contexto total de casos fallados por ese Tribunal la cifra es nimia ${ }^{102}$.

\section{CONCLUSIONES}

1. Debemos resaltar que, no cabe duda, que la lucha por el reconocimiento de los derechos del hombre tiene su origen en el reconocimiento a la libertad religiosa y de conciencia.

2. No parece existir cuestionamiento por parte de la doctrina de la existencia del derecho humano a la libertad religiosa. Es así como ha sido reconocido en numerosos instrumentos internacionales sobre derechos humanos, incluyéndolo algunos de ellos en el denominado núcleo duro de derechos. Es preciso señalar que en la mayoría de los instrumentos internacionales vigentes, el derecho a la libertad religiosa está vinculado al principio de no discriminación.

3. Las obligaciones generadas para el Estado de Chile, en cuanto al cumplimiento del derecho internacional de los derechos humanos emanarían no solo de aquellos instrumentos denominados tratados sino que eventualmente podrían surgir de las resoluciones de las organizaciones internacionales, como una fuente distinta de la costumbre internacional.

\footnotetext{
99 A modo de ejemplo ver: caso "La última tentación de Cristo" (Olmedo Bustos y otros contra Chile) en el párrafo 69 de la sentencia de 5 de febrero de 2001, la Corte Interamericana en sus consideraciones transcribe el pronunciamiento de la Corte Europea de Derechos Humanos en varios casos conocidos por esta última por violación a la libertad de pensamiento y expresión; caso "De los niños de la calle" (Villagrán Morales y Otros contra Guatemala) en el párrafo 135 de la sentencia sobre el fondo de 19 de noviembre de 1999, la Corte Interamericana se refiere a la postura adoptada por la Corte Europea de Derechos Humanos en materia de detenciones y cita varios casos conocidos por ese tribunal; caso Almonacid Arellano y otros contra Chile, en el párrafo 100 de la sentencia de 26 de septiembre de 2006, la Corte Interamericana cita: "ECHR, Case Kolk and Kislyiy v. Estonia, Judgment of 17 January 2006" a propósito del tratamiento sobre los crímenes de lesa humanidad por parte de la Corte Europea de Derechos Humanos. Casos disponibles en http://www.corteidh.or.cr/casos.cfm .

100 Martin (2004) pp. 231-232. El Tribunal Europeo de Derechos Humanos es el órgano jurisdiccional establecido por el Convenio Europeo para la salvaguardia de los derechos humanos y las libertades fundamentales (también Convenio Europeo de Derechos Humanos) y el Comité de Derechos Humanos es el órgano de vigilancia del Pacto Internacional de Derechos Civiles y Políticos.

101 El artículo 9 del Convenio Europeo para la salvaguardia de los derechos humanos y las libertades fundamentales establece la libertad de pensamiento, de conciencia y de religión.

102 Ver Annual Report 2006 del Tribunal Europeo de Derechos Humanos, donde registra 13 casos por violación al artículo 9 del Convenio Europeo de Derechos Humanos según estadísticas que abarca el período comprendido entre 1999 y 2006 (páginas 108 y 109) Disponible en: <http://www.echr.coe.int/ NR/rdonlyres/4729C3F9-D38F-42AC-8584-BCA56E26BC5C/0/Annual_Report_2006.pdf> [fecha de consulta: 4 de noviembre de 2007].
} 
4. Son muy escasas las sentencias en materia de violación al derecho humano de libertad religiosa y particularmente lo es en el caso del Sistema Interamericano, por lo que es imposible afirmar la existencia de una "jurisprudencia” al respecto.

5. Estimamos que el mayor aporte del Derecho Internacional Público al concepto de libertad religiosa viene dado por el Sistema Internacional de Protección de los Derechos Humanos a través de los órganos no jurisdiccionales y jurisdiccionales, que se encargan de supervigilar y garantizar el pleno cumplimiento de las obligaciones contraídas por los Estados en la promoción y protección del derecho a la libertad religiosa, como un derecho humano más.

\section{BIBLIOGRAFÍA CITADA}

Artola, Miguel (1982): Textos fundamentales para la Historia (Madrid, Alianza Editorial) $638 \mathrm{pp}$.

BAsterra MontSERrat, Daniel (1989): El derecho a la libertad religiosa y su tutela jurídica (Madrid, Editorial Civitas) 487 pp.

BeCERra RAmíreZ, Manuel (2005): "Las nuevas fuentes del derecho Internacional y su aplicación en el derecho interno”, en: MÉNDEZ SILVA, Ricardo (coord.), Derecho y Seguridad Internacional. Memoria del Congreso Internacional de culturas y sistemas jurídicos comparados (Instituto de Investigaciones Jurídicas de la Universidad Nacional Autónoma de México) 674 pp.

BLÁZQUEZ, José María (2005): “Constantino el grande y la Iglesia” Publicación: Alicante: Biblioteca Virtual Miguel de Cervantes. Serie: Roma, Baja romanidad y cristianismo. Estudios. Disponible en: < http://descargas.cervantesvirtual.com/servlet/SirveObras/12371956448017188532624/014934.pdf?incr=1> [fecha de consulta: 16 de enero de 2008].

Boyle, Alan and CHINKIn, Christine (2007): The Making of International Law (New York, Oxford University Press) 338 pp.

Cançado Trindade, Antônio A. (2001): El Derecho Internacional de los Derechos Humanos en el siglo XXI (Santiago, Editorial Jurídica de Chile) 455 pp.

Cançado Trindade, Antônio A. y Ventura Robles, Manuel (2004): El futuro de la Corte interamericana de derechos humanos (San José de Costa Rica, Corte Interamericana de Derechos Humanos) 461 pp.

Carrillo Salcedo, Juan Antonio (1976): Soberanía del Estado y Derecho Internacional (Madrid, Editorial Tecnos ) 448 pp.

Carrillo Salcedo, Juan Antonio (1985): El derecho internacional en un mundo de cambio (Madrid, Editorial Tecnos) 351 pp.

CARRILlO SALCEDO, Juan Antonio (1999): Dignidad frente a barbarie. La Declaración Universal de Derechos Humanos, cincuenta años después (Madrid, Editorial Mínima Trotta) 153 pp.

Carrillo Salcedo, Juan Antonio (2003) El Convenio Europeo de Derechos Humanos (Madrid, Editorial Tecnos) 157 pp.

Cena Egaña, José Luis (2004): Derecho Constitucional Chileno Tomo II. Derechos, Deberes y Garantías (Santiago de Chile, Ediciones Universidad Católica de Chile) 733 pp. 
CORTÍNEZ CASTRO, René (1995): Libertad religiosa y principio de igualdad: La personalidad jurídica de las iglesias en el derecho público chileno: Estudio de la situación de la Iglesia Católica y de las Iglesias Evangélicas. Comparación con el Derecho Español (Tesis de Magíster en Derecho Público, mención en Derecho Constitucional Pontificia Universidad Católica de Chile, Santiago de Chile) 363 pp.

DAVIS, Derek H. (2001): "La evolución de la libertad religiosa como un derecho humano", Temas de la Democracia. Periódico electrónico del Departamento de Estado de Estados Unidos, noviembre de 2001, vol. VI n ${ }^{\circ}$ 2. Disponible en: <http://usinfo.state.gov/ journals/itdhr/1101/ijds/ijds1101.pdf>[fecha de consulta: 30 de enero de 2008].

Evans DE LA CUADRA, Enrique (1999): Los derechos constitucionales. Tomo I Segunda edición actualizada (Santiago de Chile, Editorial Jurídica de Chile) 376 pp.

FIX ZamUdiO, Héctor (1998): "La libertad religiosa en el sistema interamericano de protección de los derechos humanos”, en: MARTínEZ-TORRón, Javier (edit.), La libertad religiosa y de conciencia ante la justicia constitucional. Actas del VIII Congreso internacional de derecho eclesiástico del estado. Granada, 13-16 de mayo de 1997 (Granada, Editorial Comares) pp. 95-105.

FRÜHLing E. Hugo (1990): "El sistema universal de protección de los derechos humanos”, en: Medina Quiroga, Cecilia (edit.), Derecho Internacional de los Derechos Humanos. Manual de enseñanza (Santiago de Chile) pp. 31-61

Gutiérrez EsPada, Cesáreo (1995): Derecho Internacional Público (Madrid, Editorial Trotta) 699 pp.

Llanos ManCILla, Hugo (2005): Teoría y práctica del derecho internacional público. Introducción y fuentes. Tercera edición actualizada (Santiago de Chile, Editorial Jurídica de Chile) 649 pp.

LlorCA, Bernardino S.I. (1976): Historia de la Iglesia Católica. En sus cuatro grandes edades: Antigua, Media, Nueva, Moderna. Tomo I: Edad Antigua. La Iglesia en el mundo grecorromano (Madrid, Biblioteca de autores cristianos) $884 \mathrm{pp}$.

Mariño Menéndez, Fernando (2005): Derecho Internacional Público. Parte general (Madrid, Editorial Trotta) 694 pp.

MARTIN, Claudia et al. (2004): "La Corte Interamericana de Derechos Humanos: funciones y competencia”, en: MARTIn, Claudia; RodrígueZ-Pinzón, Diego y Guevara, José A. (comp.), Derecho Internacional de los Derechos Humanos (México, Universidad Iberoamericana, A.C.; Washington Collage of Law, American University y Fontamara) pp. 209-277.

Medina Quiroga, Cecilia et al. (1990): Derecho Internacional de los Derechos Humanos. Manual de enseñanza (Santiago de Chile, editora Cecilia Medina) 258 pp.

Millán Moro, Lucía (1990): La Opinio iuris en el derecho internacional contemporáneo (Madrid, Editorial Centro de Estudios Ramón Areces) 201 pp.

Nogueira AlCalÁ, Humberto (2006): "La libertad de conciencia, la manifestación de creencias y la libertad de cultos en el ordenamiento jurídico chileno", Ius et Praxis [online] vol. XII $\mathrm{n}^{\circ}$ 2, pp. 13-41. Disponible en: <http://www.scielo.cl/ scielo.php?script=sci_arttext \&pid=S0718-00122006000200002\&lng=es\&nrm=iso > [fecha de consulta: el 12 de febrero de 2008] ISSN 0718-0012. 
PÁramo Argüelles, Juan Ramón de y AnsuÁtegui Roig, Francisco Javier (1998): "Los derechos en la revolución inglesa", en: PECES-BARBA MARTÍnEZ, Gregorio et al., Historia de los derechos fundamentales. Tomo I Tránsito a la modernidad siglos XVI y XVII (Madrid, Editorial Dykinson S.L.) pp. 747-796.

Pastor Ridruejo, José Antonio (2003): Curso de Derecho Internacional Público y Organizaciones Internacionales (Madrid, Editorial Tecnos) 813 pp.

PeCes-BArba MartíneZ, Gregorio et al. (1998): "El Edicto de Nantes" en: Historia de los derechos fundamentales. Tomo I Tránsito a la modernidad siglos XVI y XVII (Madrid, Editorial Dykinson S.L.)

PreCht PiZARro, Jorge (2001) Derecho Eclesiástico del Estado de Chile. Análisis históricos y doctrinales (Santiago de Chile, Ediciones Universidad Católica de Chile) 347 pp.

PRECHT PIZARRO, Jorge (2006): 15 Estudios sobre Libertad Religiosa en Chile (Santiago de Chile, Ediciones Universidad Católica de Chile) 274 pp.

Robertson, A. H. (1972): Human Rights in the world (Gran Bretaña, Manchester University Press) 280 pp.

Rodríguez CARrión, Alejandro J. (2006): Lecciones de Derecho Internacional Público (Madrid, Editorial Tecnos) 589 pp.

RODRíguez RESCIA, Víctor Manuel (1994): "Eficacia jurídica de la jurisprudencia de la Corte Interamericana de Derechos Humanos", en: NieTO NAVIA, Rafael (edit.), La Corte y el Sistema Interamericano de Derechos Humanos (San José, Costa Rica. Corte IDH) pp. $459-479$.

Salinas ARANeda, Carlos (2004): Lecciones de Derecho Eclesiástico del Estado de Chile (Valparaíso, Ediciones Universitarias de Valparaíso Pontificia Universidad Católica de Valparaíso, Chile) 474 pp.

SALVIOLI, Fabián Omar (1999):“"El aporte de la Declaración Americana de 1948 para la protección internacional de los derechos humanos”, en: Anuario de Derecho Universidad Austral no 5 (Buenos Aires, Argentina) pp. 13-26.

Silva Bascuñán, Alejandro (2006): Tratado de Derecho Constitucional. Tomo XI. De los derechos y deberes constitucionales. Derecho a la vida e integridad de la persona. Igualdad ante la ley en la protección de los derechos. Derecho a la honra y a la vida privada. Libertad de conciencia y religión (Santiago de Chile, Editorial Jurídica de Chile) 313 pp.

Sobrino Heredia, José Manuel (2006): "Los medios jurídicos de acción: El derecho de las organizaciones internacionales", en DIEZ DE VELASCO Las Organizaciones Internacionales (Madrid, Editorial Tecnos) pp. 128 a 146.

Terol Becerra, Manuel José, Álvarez-Osorio Micheo, Fernando y Barrero OrTEGA, Abraham (2005): Las grandes decisiones del Tribunal Europeo de Derechos Humanos (Valencia, Tirant lo blanch) $214 \mathrm{pp}$.

Truyol y Serra, Antonio (1984): Los Derechos Humanos (Madrid, Editorial Tecnos) $200 \mathrm{pp}$.

Urios Moliner, Santiago (1993): "La protección internacional de los Derechos Humanos”, en: Durán Lalaguna, Paloma (coord.), Manual de Derechos Humanos (Granada, Editorial Comares) 281 pp. 
Badilla Poblete, Elvira "El concepto de libertad religiosa en algunos instrumentos internacionales..."

Villán Durán, Carlos (2001): “La Declaración universal de derechos humanos en la práctica de Naciones Unidas”, en: BlanC AlTEMIR, Antonio (edit.) La protección internacional de los derechos humanos a los cincuenta años de la Declaración Universal (Madrid, Editorial Tecnos ) 329 pp.

\section{JURISPRUDENCIA}

\section{CORTE INTERNACIONAL DE JUSTICIA:}

Caso relativo a las actividades militares y paramilitares en Nicaragua y contra Nicaragua (Nicaragua contra los Estados Unidos de América) 1986 Fondo del asunto, en http:// www.icj-cij.org/homepage/sp/files/sum_1948-1991.pdf.

Corte Interamericana de Derechos Humanos:

Opinión Consultiva OC-10/89 del 14 de julio de 1989. Serie A No 10, Interpretación de la Declaración Americana de los Derechos y Deberes del Hombre en el marco del artículo 64 de la Convención Americana sobre Derechos Humanos en http:// www.corteidh.or.cr/opiniones.cfm

Caso Castillo Petruzzi y otros contra Perú, Sentencia de 20 de mayo de 1999. Serie C no 59. Consultado en http://www.corteidh.or.cr/casos.cfm

Caso de los "Niños de la calle" (Villagrán Morales y Otros). Sentencia de 19 de noviembre de 1999. Serie C no 63. Consultado en : http://www.corteidh.or.cr/casos.cfm

Caso Tribunal Constitucional contra Perú, sentencia de 31 de enero de 2001. Serie C no 71 Consultado en http://www.corteidh.or.cr/casos.cfm

Caso "La última tentación de Cristo" (Olmedo Bustos y otros) contra Chile. Fondo, reparaciones y costas. Sentencia de 5 de febrero de 2001 Serie C No 73 en www.corteidh.or.cr

Caso Juan Humberto Sánchez contra Honduras Sentencia de 7 de junio de 2003. Serie C no 99 Consultado en http://www.corteidh.or.cr/casos.cfm

Comisión Interamericana de Derechos Humanos:

Caso 12.219 Cristian Daniel Sahli Vera y otros contra el Estado de Chile de 10 de marzo de 2005, Informe sobre el fondo No 43/05 [Comisión Interamericana de Derechos Humanos] consultado en: http://www.cidh.oas.org 